\title{
Life stages, demographic rates and leaf damage for the round-leaved orchids, Platanthera orbiculata (Pursh.) Lindley and P. macrophylla (Goldie) P.M. Brown in a northern hardwood forest, New Hampshire, USA.
}

\begin{tabular}{|r|l|}
\hline Journal: & Botany \\
\hline Manuscript ID & cjb-2016-0164.R1 \\
\hline Manuscript Type: & Article \\
\hline Date Submitted by the Author: & 23-Aug-2016 \\
\hline Complete List of Authors: & $\begin{array}{l}\text { Cleavitt, Natalie; Cornell University, } \\
\text { Berry, Eric; Saint Anselm College Biology Department } \\
\text { Hautaniemi, Jill; Dickinson College, Biology Department } \\
\text { Fahey, Timothy; Cornell University College of Agriculture and Life Sciences, } \\
\text { Natural Resources }\end{array}$ \\
\hline Keyword: & orchid, demography, herbivory threshold, life stage, conservation \\
\hline & \multicolumn{2}{|c}{} \\
\hline
\end{tabular}


Life stages, demographic rates and leaf damage for the round-leaved orchids, Platanthera orbiculata (Pursh.) Lindley and P. macrophylla (Goldie) P.M. Brown in a northern hardwood forest, New Hampshire, USA.

Natalie L. Cleavitt, Department of Natural Resources, Cornell University, Ithaca, NY 14853

Email: nlc4@cornell.edu

Corresponding author - Mailing address: 55 Perch Pond Road, Holderness, NH 03245

Eric J. Berry, Biology Department, St. Anselm College, 100 Saint Anselm Drive, Manchester, NH 03102

Email: EBerry@Anselm.Edu

Jill Hautaniemi, Dickinson College, Department of Environmental Science, 28 North College Street, Carlisle, PA 17013-2727

Current address: Department of Forest and Wildlife Ecology, University of Wisconsin, Madison, WI 53715

Email: hautaniemi@wisc.edu

Timothy J. Fahey, Department of Natural Resources, Cornell University, Ithaca, NY 14853 Email: tjf5@cornell.edu 


\begin{abstract}
Terrestrial orchids are especially susceptible to population declines and hence are the focus of plant conservation efforts worldwide, but the life history and demography of heterotrophic orchids is not well understood. Our objective was to quantify life stage transition rates for a species pair of rare round-leaved orchids (Platanthera spp.) in a northern hardwood forest. Marked individuals were measured over five years, including: leaf area, damage by herbivores and pathogens, flowering and seed production. Germination trials were also conducted. Vital rates were very similar for the two species, which were about equally abundant despite large differences in seed production. Mortality was twice as high for juvenile as for adult stages and juvenile abundance was markedly lower than for adults. Both species are vulnerable to leaf damage by invertebrates and fungi and exhibit clear leaf area thresholds for progression across life stages, both suggesting a delicate carbon balance for these mixotrophic orchids. The likely role of mycosymbiont distribution in facilitating seedling establishment deserves further detailed study to inform conservation efforts as these and other orchid species face an uncertain future owing to rapid environmental change and increasing pressure from white-tailed deer herbivory in the northern part of their range.
\end{abstract}

Keywords: orchid, demography, conservation, herbivory threshold, life stage 


\section{Introduction}

Orchids are the focus of plant conservation efforts worldwide because they are highly susceptible to population declines owing largely to their complex interactions with other organisms (Fay et al. 2015). In northeastern North America, the sensitivity of terrestrial orchids results from their close associations with different fungi in various life stages (Zelmer et al. 1996; Rasmussen et al. 2015) and their susceptibility to targeted herbivory by growing populations of white-tailed deer (Knapp and Wiegand 2014). Despite documented decline in orchids in northeastern North America (e.g., Reddoch and Reddoch 2007; Bertin 2013; Knapp and Wiegand 2014) and general interest in orchids for conservation, large gaps in our understanding of orchid life history and demography remain for the majority of species in North America (Reddoch and Reddoch 2007).

The species pair of round-leaved orchids, Platanthera orbiculata (Pursh.) Lindl. and $P$. macrophylla (Goldie) P.M. Brown, is emblematic. Both species are heterotrophic, terrestrial orchids endemic to North America, and both are listed as rare in four of the six New England states: Vermont (S2), Massachusetts (S1S2), Connecticut (SH) and Rhode Island (SH) (Nature Serve 2015; USDA, NRCS 2015). Additionally, P. macrophylla is listed as endangered or threatened at the northern extent of its range in five Canadian provinces and at its southern extent in Pennsylvania. Platanthera orbiculata has a broader range than P. macrophylla (Sheviak 2003) and is also listed as extirpated, endangered or threatened in New Jersey, Illinois, Wyoming, Indiana, and Tennessee, but has yet to be ranked in the majority of its range (Nature Serve 2015; USDA, NRCS 2015). We use this species pair to inform conservation of these orchids in the Northeast. 
Much of the published data on these two orchids comes from the work of Reddoch and Reddoch $(1993,1997)$ who differentiated the species pair primarily on the basis of flower morphology. They also published the only data on the life history of these orchids: based on five plants of $P$. orbiculata, the young single-leaf stage was followed by a two-leaf stage and finally flowering individuals (Reddoch and Reddoch 1997). In addition, they found that individuals of $P$. orbiculata may live up to at least 15 years and flower repeatedly during this time. Unforunately, the population of $P$. orbiculata studied by these authors was extirpated by deer browsing pressure (J. Reddoch, pers. comm.). Similar observations for the generally rarer, $P$. macrophylla, are lacking (Reddoch and Reddoch 1997) and the illusive underground protocorm stage has not been previously studied for either species in situ.

Differences in recovery of showy lady's slippers (Cypripedium reginae Walter) after moderate $(<50 \%)$ and severe herbivory $(>65 \%)$ by white-tailed deer (Gregg 2004) suggests that there may be thresholds for herbivory effects in terrestrial orchids. Such sensitivity to herbivory likely reflects the intricate carbon balance, as an increasing number of terrestrial orchids are now recognized to employ mixotrophic carbon acquisition with dependence upon mycosymbionts (Bellino et al. 2014; Gonneau et al. 2014; Yagame et al. 2012). To address concerns about the effects of herbivory on these species, data are needed on thresholds for leaf damage and the relationship between leaf damage and vital rates.

The objective of the present study was to contribute to understanding of the demography of these threatened, co-occurring heterotrophic orchids and thereby to more generally inform conservation efforts for heterotrophic terrestrial orchids. We delineated the life stages and 
quantified the transition rates and flowering and fruiting based on five years of measurements of marked individuals in a northern hardwood forest, New Hampshire (Fig. 1). We evaluated the principal threats from herbivores and pathogens and the responses of the plants to leaf damage. At this study site the two species co-occur in similar abundance, and we sought evidence of demographic factors accounting for this general observation. We hypothesized that survival and growth of individuals would be similar for the two species as Franco and Silvertown (2004) showed that these demographic factors were more important than fecundity in controlling population growth in iteroparous forest herbs. However, we anticipated further complexities associated with the likely mixotrophic life history of these plants.

\section{Methods}

Study site. The Hubbard Brook Experimental Forest (HBEF) is located in north-central New Hampshire, USA ( $43^{\circ} 56^{\prime} \mathrm{N}, 71^{\circ} 45^{\prime} \mathrm{W}$ ) (Fig. 1). Detailed descriptions of climate, hydrology, topography, and vegetation of the HBEF are presented in Likens and Bormann (1995). Soils are predominantly well-drained acid Spodosols (Haplorthods) of sandy-loam texture formed from glacial till. Soils generally decline in thickness with increasing elevation (Johnson et al. 2000), but considerable variation in soil properties is associated with till characteristics, topographic position and internal drainage (Bailey et al. 2014). The forest is in a 3160 ha valley with overstory vegetation dominated by northern hardwoods: sugar maple (Acer saccharum Marsh., American beech (Fagus grandifolia Ehrh.), and yellow birch (Betula alleghaniensis Britt.), which comprise over $90 \%$ of the forest basal area (van Doorn et al. 2011). The valley covers an elevation range of 200 to $1010 \mathrm{~m}$. The HBEF is mostly second-growth forest developed following 
logging in the late $19^{\text {th }}$ and early $20^{\text {th }}$ century with most of the forest currently about 100 years old.

Marked individuals. Beginning in the summer of 2011, all individuals of the round-leaved orchids sighted in the HBEF have been marked and mapped. The number of individuals of each species in the sample has been similar over time (Table 1). Individuals were marked with a bright pink PVC flag and given a unique number. The location of groups of orchids were recorded in a GPS data base gathered using handheld Garmin GPSmap 62s (Fig. 1). Individual orchids are additionally mapped relative to each other within groups by compass and meter tape. Orchids were visited three times a season from 2011 to 2015 for flowering individuals (early spring, July for flower data, late August-early Sept for capsule data) and at least once a season for non-flowering individuals to record life stage and leaf data. From 2011 to 2014, leaf area was estimated for all marked individuals by measuring the length and width of the leaves and calculating an elliptic area $\left(\mathrm{cm}^{2}\right)$. For previously marked individuals, these measurements were taken in early July, while newly marked individuals were assessed at the time of their marking. The percent of leaf damaged was estimated visually and the cause of the damage was also recorded at all visits. Flower measurements and seed capsule data were collected from 2013 to 2015.

Seed germination trials were conducted for each species beginning in autumn 2013. Capsules were collected on 25-27 Sept and placed in 5 X $5 \mathrm{~cm}$ packets made from $53 \mu \mathrm{m}$ plankton netting with three replicate packets per species. One capsule was placed in each packet, and capsules were broken open after the packets were sewn shut. Packets were incubated in the field under 
the leaves of mature orchids in Hubbard Brook starting on 9 Oct 2013. Germination packets were evaluated in the field with 10-20 X handlens and grid on 25 June 2014. Photographs of germinated seedlings were taken under the compound scope from one packet per species. In 2015, we conducted seed dilutions to estimate the number of seeds per capsule and to create replicate seed packets with a better estimate of seed number. We use these estimates of seeds per capsule with the germination counts from 2014 to obtain a preliminary estimate of germination percentage for the two species.

Statistical analyses. Due to the unequal sample sizes between taxa, years, life stages and transitions, continuous variables such as leaf area and percent of leaf area damaged were compared by non-parametric (ranks) tests. Categorical response variables such as transition classes and damage agents were compared by likelihood-ratio $G^{2}$ tests. Analyses were performed in JMP Pro version 10 (SAS Institute 2012) and MINITAB ${ }^{\circledR}$ Release 14.1 (MINITAB 2003).

Life expectancy values for each species were estimated by calculating the fundamental matrix from the 4x4 transition matrix (appendix Fig. A1) that was composed of the life history transitions for the four orchid life-history stages: Juvenile, Immature, Vegetative adult, and Flowering adult. The fundamental matrix indicates the average amount of time individuals of each life history stage spend in the stage (Caswell, 2001). Age at death (life expectancy) for a given life history stage was calculated as the sum of its column in the fundamental matrix. Age at death for survivors through all the stage classes was calculated as the sum of the diagonal elements in the fundamental matrix. To calculate the average age at death with confidence 
intervals we used bootstrap analysis to generate 3,000 resamples. For each iteration, a new transition matrix was produced by resampling with replacement the original demographic data. Life expectancy values were calculated from the fundamental matrix produced by each new resampled transition matrix. Confidence intervals were obtained from the resamples using the nonparametric "Percentile Method"' (Scheiner and Gurevitch 1993). Ninety-five percent confidence intervals are reported in the Results, and for statistical comparisons we used adjusted confidence intervals reported in Payton et al. (2003). These adjusted confidence intervals were based on a ratio of standard errors of 2 , which corresponds to $85.6 \%$ confidence levels for individual intervals. We used these intervals because their values have been shown to better approximate an $\alpha=0.05$ test than non-overlapping 95\% confidence intervals, which creates overly conservative comparisons (Payton et al. 2003). Age-specific survivorship for individuals in each stage were calculated from the transition matrix using equation 5.13 in Caswell (2001). Bootstrapping and survivorship calculations were performed using MATLAB R2015a (Mathworks 2015).

\section{Results}

Life stages and fecundity. Both Platanthera macrophylla and P. orbiculata progress through five life stages: 1) underground germinant / protocorm, 2) above ground juvenile with a single linear leaf (at least 2:1 in length:width), 3) an immature stage with single round leaf, 4) vegetative adult with two rounded leaves and 5) flowering adult with two rounded basal leaves and a raceme (Fig. 2). 
For the four stages with aboveground leaves, leaf sizes differed significantly among stages $\left(\mathrm{X}^{2}=\right.$ 459; df $=3 ; \mathrm{p}<0.0001)$ with marked increases in mean leaf area (Fig. 3). There were no significant differences in leaf area between years $\left(X^{2}=1.53 ; \mathrm{df}=3 ; \mathrm{n} . \mathrm{s}.\right)$ or species $\left(\mathrm{X}^{2}=0.50\right.$; df $=1$; n.s.).

Although there was some year-to-year variation in vital rates (appendix Fig. A2), the smaller stages of Juvenile and Immature plants had mortality rates that were approximately double those of adults for both $P$. macrophylla $\left(20.8 \%\right.$ v. $\left.12.8 \% ; G^{2}=3.68 ; \mathrm{df}=1 ; P=0.055\right)$ and $P$. orbiculata (22.1\% v. 9.4\%; $\left.G^{2}=8.27 ; \mathrm{df}=1 ; P<0.005\right)$ (Fig. 4). Vital rates between the two species were very similar, with the exception of greater stasis among flowering $P$. orbiculata, indicating that this species was more likely to flower in successive years (Fig. 4). This difference was also reflected in a significantly higher proportion of $P$. orbiculata adults initiating an inflorescence, although the proportion of adults successfully completing flowering was not different between the two species (Table 2). Flowering adults of $P$. orbiculata produced significantly more flowers per plant, but this difference did not lead to significantly more swollen ovaries (evidence of successful pollination) or fruits per flowering plant (Table 2).

A preliminary sampling of three seed capsules per species indicated that the seed capsule volume (mean; range) for $P$. macrophylla $\left(1,716 \mathrm{~mm}^{2} ; 1,115-2,729 \mathrm{~mm}^{2}\right)$ was much great than for $P$. orbiculata $\left(639 \mathrm{~mm}^{2} ; 498-918 \mathrm{~mm}^{2}\right)$. Despite this size difference, the mean number of seeds per capsule (mean; range) for $P$. macrophylla $(2,539 ; 1,710$ - 3,927) was similar to $P$. orbiculata $(2,223 ; 2,120-2,325)$. Based on limited sample sizes $(\mathrm{N}=3$, per species $)$, germination 
percentages were nearly identical between the species (mean $\pm \mathrm{SE})$, P. macrophylla $(48 \pm 8 \%)$ and $P$. orbiculata $(48 \pm 9 \%)$.

Life expectancy and survivorship. The mean age at death (life expectancy) for newly established Juveniles (mean; 95\% CI) was lower for $P$. macrophylla $(5.59 ; 3.88-7.62)$ than for $P$. orbiculata $(6.09 ; 4.20-8.75)$, a difference that was not statistically significant based on the criterion of non-overlapping $85.6 \%$ confidence intervals, which approximates $\alpha=0.05$ test for this analysis (see Methods). Similarly, the life expectancy of adults who survived through all the stages (mean; 95\% CI) was lower for P. macrophylla (11.42; 9.64 - 13.82) than for P. orbiculata $(12.80 ; 10.43$ - 15.99), a difference that was also not statistically significant. The survivorship curve for Juveniles was nearly identical for the two species and revealed that although most individuals die within the first 10 years, a small fraction of adults (3-5\%) may live for 20 years or more (Fig. 5). The average time spent in each life history stage for surviving individuals was the same for both species, with the exception that $P$. orbiculata spends greater time in the adult stage before death, which accounts for the difference in life expectancy described above.

Leaf damage. Leaf damage $\left(\%\right.$ of leaf area) did not differ significantly between species $\left(\mathrm{X}^{2}=\right.$ 3.66; $\mathrm{df}=1 ; \mathrm{p}=0.06)$. Leaf damage did vary significantly among transition classes $\left(\mathrm{X}^{2}=49.6\right.$; $\mathrm{df}=4 ; \mathrm{p}<0.001)$, years $\left(\mathrm{X}^{2}=70.9 ; \mathrm{df}=2 ; \mathrm{p}<0.001\right)$, and life stages $\left(\mathrm{X}^{2}=11.8 ; \mathrm{df}=3 ; \mathrm{p}=\right.$ 0.008) (Fig. 6). Orchids that died had significantly higher leaf damage in the preceding growing season ( $>25 \%$ of the leaf area damaged; Fig. 6). Additionally, orchids that regressed (went to demographically earlier stage) had greater leaf damage in the preceding season $(>15 \%)$ than those that maintained stasis (remained in the same stage) or grew (progressed to the next 
demographic stage $)(<15 \%$; Fig. 6). Leaf damage was greater in 2012 than in the following two years for both species. Higher leaf damage was generally observed for the immature and vegetative adults than for the juveniles or flowering adults, but the differences in sample sizes precluded detection of these differences; only the differences between adults (less damage for flowering than vegetative) was statistically significant (i.e., p $<0.05$; appendix Fig. A3).

The agents of leaf damage varied significantly in frequency and impact (Fig. 7). Gastropod (slug and snail) herbivory was scored on $58 \%$ of the orchids, but only affected about $12 \%$ of the leaf area on average (median of $5 \%$; Fig. 7). In contrast, fungal damage only occurred on $12 \%$ of the orchids, but affected about $50 \%$ of the leaf area for infected individuals (Fig. 7). Additionally, across years slug herbivory was a constant presence, while fungal attack was significantly higher in 2012 (appendix Table A1).

\section{Discussion}

Species comparisons. We observed that these two co-occurring and closely related species of orchid exhibit very similar vegetative features including leaf size, susceptibility to leaf damage, damage agents and the effect of leaf damage on vital rates. This result confirms earlier work of Reddoch and Reddoch $(1993,1997)$ from southern Canada. However, the species differ in several parameters relating to flowering adults and fecundity. The more widespread Platanthera orbiculata produces more flowers per raceme resulting in greater flower density and is more likely to remain a flowering individual for several consecutive years leading to a significantly greater proportion of flowering individuals compared to the more narrowly distributed $P$. macrophylla. This greater proportion of flowering individuals for P. orbiculata, combined with 
comparable (or even slightly greater) fruit production per flowering plant, means that $P$. orbiculata populations produce substantially more seed capsules than P. macrophylla.

Given the greater seed production of $P$. orbiculata, one might expect this species to be more abundant in our study area than its congener $P$. macrophylla, yet we have encountered nearly the same number of individuals for both species during the five years of our study (Table 1). One possible explanation is that greater seed production does not significantly increase population size because fecundity has much less impact on the population growth than other life-history characteristics such as juvenile growth or adult survival. This explanation is consistent with a comparative demography study by Franco and Silvertown (2004), which showed that population growth among iteroparous forest herbs was much more sensitive to changes in survival and growth than to changes in fecundity. That is not to say that fecundity is unimportant - fecundity contributes as much as $20-30 \%$ to changes in population growth in moderately long-lived plants (Franco and Silvertown 2004) such as P. macrophylla and P. orbiculata - it is just that fecundity has much less of a population impact than growth and survival. Indeed, quantification of the protocorm transition stage appears most critical to complete the life table and quantitatively model the population demography of these orchids.

Another possible explanation for the similarity in abundance of the two species despite the greater fecundity of $P$. orbiculata is that establishment in the two species is determined by something other than seed dispersal, such as the distribution and abundance of compatible fungal mycorrhizal partners. As obligate mycoheterotrophs, these orchids depend completely on resources from fungi to grow until they develop into an aboveground photosynthetic stage 
(McCormick et al. 2012); based on our germination trials these species persist in the protocorm stage for several years (see below). Given this level of dependence on mycorrhizae for seedling recruitment, the distribution and abundance of compatible mycorrhizae probably plays an important role (perhaps the most important role) in determining the distribution and abundance of $P$. macrophylla and P. orbiculata orchids across the landscape.

Life stages. Our life stage delineations bear several similarities to those by Reddoch and Reddoch (2007) for Platanthera hookeri, a closely related species, including juveniles with one smaller, linear leaf; an alternation between vegetative and flowering adult stages; and the rarity of dormancy. The main differences in the life stages between these taxa were a lack of immature, one-rounded leaf stage for $P$. hookeri, a lack of a terminal regressive stage in our two species, and the successful recruitment of some portion of juveniles into the populations in our study (Reddoch and Reddoch 2007).

Our observations of germinants agree with those of Zelmer et al. (1996) for P. orbiculata that seeds of these orchids can germinate without an established mycobiont. Although our germination trials have not yet produced any single leaf juveniles, current results point to a belowground protocorm stage that lasts for at least four, but likely several more, years. Establishment of orchids is a complex process dependent on favorable conditions for seed germination, mycobiont presence, and sufficient carbon supply for the mycobiont and thereby the young orchid (Rasmussen et al. 2015). Several studies have also emphasized that seedling orchids often depend upon different endophytes than the mycorrhizae of mature plants (Zelmer et al. 1996; Rasmussen et al. 2015). In addition, orchid seedlings appear to be less specific in 
mycobiont selection than mature orchids where mycorrhizal partners have been documented as important aspects of niche partitioning (Jacquemyn et al. 2012; McCormick and Jacquemyn 2014). Clearly, more detailed work on the fungal partners for these orchids will be necessary to deepen understanding of their ecology and further their conservation.

Three leaf area thresholds appear to define life stage transitions for both orchid species (Fig. 3). This pattern suggests that photosynthesis plays an essential role in the life history and maturation of these orchids. Although mixotrophy has been documented in an Asian terrestrial forest species of Platanthera and suggested for several European species (Yagame et al. 2012), the degree and presence of mixotrophy in these two orchid species is currently unknown. Some recent studies from Europe have suggested that mixotrophic, terrestrial forest orchids use photosynthesis to buffer against limitations in fungal carbon sources and ensure seed development (Bellino et al. 2014; Gonneau et al. 2014). The fact that flowering adults are significantly larger than vegetative adults for our two species strongly points to the importance of increased photosynthetic capacity to reproduction in $P$. orbiculata and $P$. macrophylla. However, the existence of a fungal carbon source for the adult stages of these orchids remains to be demonstrated.

Leaf damage. The strong relationship between amount of leaf area damaged and trajectory of life transitions hints at a rather delicate carbon balance. For example, high leaf area damage was clearly associated with a higher level of mortality in both species (Fig. 6). Both species set their vegetative bud and initiate new roots for the following year by August of the current year (Currah et al. 1990; Cleavitt, pers. obs.); hence, death is generally pre-determined if the 
individual lacks the resources to form a bud. In only one instance was death observed from damage of an already set bud in a particularly exposed location. Another indication of the delicate carbon balance in these orchids is the propensity for juveniles to operate as spring ephemerals, often only appearing aboveground for a few weeks in early spring (Cleavitt, pers. obs.). The rarity of dormancy in these species could also be interpreted as a consequence of rarity of having enough stored resources to use this stress response strategy (Fig. 4 and appendix Fig. A2). In other temperate, terrestrial orchids, dormancy has been induced by experimental removal of leaf surface area (Shefferson et al. 2005); however, removal of leaf surface area was much more strongly related to mortality in this study.

The agents of leaf damage varied in frequency, severity and impact among years. Slug and snail herbivory was the most common form of damage, but it seldom resulted in more than $10 \%$ of the leaf area removed (Fig. 6). Fungal damage could be fairly devastating, but showed large variation between years. In 2012, the leaves of many of the orchids turned brown and blistery soon after leaf expansion in May. Interestingly, we documented unusually high fungal damage in this year on sugar maple seedlings within HBEF (Cleavitt et al. 2014) by a Rhizoctonia sp. (root rot and vascular system pathogen; Cleavitt et al. 2011); however, we did not confirm the identity of the pathogen on the orchids in 2012.

Implications for conservation. The number of juveniles in these populations of orchids was markedly out of balance with the number of adults (Fig. 4), indicating that the juvenile stage represents a potential population bottleneck. Populations with such limited recruitment may appear stable if adult mortality is sufficiently low, but such populations are incapable of 
significant positive population growth without an increase in recruitment (Berry et al. 2011). The need for increased juvenile recruitment to maintain these orchid populations will likely be greater in the future, as increased herbivory from white-tailed deer potentially increase adult mortality. Historically, deer were reported at very low densities in Hubbard Brook (Pletscher et al. 1989), but their populations appear to be increasing the last several years in conjunction with decreased snow depths (Campbell et al. 2010).

All life stages appear vulnerable to often fatal consequences of leaf damage taking greater than $25 \%$ of the leaf area (Fig. 6). In addition to the apparently tenuous progression to achieve the flowering adult stage, flower production is set back between $11-17 \%$ of the time by damage to the raceme and seed capsule set is relatively low (Table 2). As noted above, there is a significant difference in total seed production between the two species, and if additional research reveals that seed production is a limiting factor for population growth, the lower fecundity of $P$. macrophylla would make the species more at risk of population decline than its more fecund congener $P$. orbiculata. The population model building requires more complete data on: number of seeds that successfully germinate, the length of the protocorm stage from seed germination to aboveground juvenile and the percent of protocorms that transition to the juvenile stage. We present a strong initial framework for understanding possible population bottlenecks for these and other terrestrial orchids and future work should be aimed at rounding out knowledge of these more cryptic early life stages. 


\section{Acknowledgements}

This work was supported by NSF-LTER DEB-0423259 to TJ Fahey and the NSF-REU site program administered by the Hubbard Brook Research Foundation and Plymouth State University, and is a contribution to the Hubbard Brook Ecosystem Study. Cindy Wood, Rachel Neugarten, Carlin Starrs, Jackson Saul and other members of "veg crew" from 2011-2015 were fellow seekers of unmarked orchid individuals. Cindy Wood has assisted with orchid visits in all years of the study. Shannon Healy assisted JH in 2013. We also thank Scott Bailey (USFS) for creating the map for Figure 1 and Kristian Gustafson for assistance digitizing the plant sketches by NLC used in our figures.

\section{References}

Bailey, S.W.; Brousseau, P.A., McGuire, K.J., and Ross, D.S. 2014. Influence of landscape position and transient water table on soil development and carbon distribution in a steep, headwater catchment. Geoderma 226-227: 279-289.

Bellino A.; Alfani, A., Selosse, M.-A., Guerrieri, R., Borghetti, M. and Baldantoni, D. 2014. Nutritional regulation in mixotrophic plants: new insights from Limodorum abortivum. Oecologia 175:875-885.

Berry, E.J.; Gorchov, D.L. and Endress, B.A. 2011. Source-sink population dynamics and sustainable leaf harvest of the understory palm Chamaedorea radicalis. In Liu, J.; Hull, V. Morzillo, A. and Wiens, J. (editors). Sources, sinks, and sustainability across landscapes. Cambridge University Press. 
Bertin, R. I. 2013 Changes in the native flora of Worcester County, Massachusetts. Journal of the Torrey Botanical Society 140: 414-452.

Campbell, J. L., Ollinger, S. V., Flerchinger, G. N., Wicklein, H., Hayhoe, K. and Bailey, A. S. 2010. Past and projected future changes in snowpack and soil frost at the Hubbard Brook Experimental Forest, New Hampshire, USA. Hydrological Processes 24: 2465-2480.

Caswell, H. 2001. Matrix population models second ed. Sinauer associates, Inc. Publishers, Sunderland, Massachusetts.

Cleavitt, N.L.; Battles, J.J., Fahey, T.J. and Blum, J. 2014. Determinants of survival over seven years for a natural cohort of sugar maple seedlings in a northern hardwood forest. Can. J. For. Res.44 (9): 1112-1121.

Cleavitt, N.L.; Fahey, T.J. and Battles, J.J. 2011. Regeneration ecology of sugar maple (Acer saccharum): seedling survival in relation to nutrition, site factors, and damage by insects and pathogens. Can. J. For. Res. 41(2): 235-244.

Currah, R.S.; Smreciu, E.A. and Hambleton, S. 1990. Mycorrhizae and mycorrhizal fungi of boreal species of Platanthera and Coeloglossum (Orchidaceae). Can. J. Bot. 68: 1171-1 181. 
Fay, M.F.; Pailler, T. and Dixon, K.W. 2015. Orchid conservation: making the links. Annals of Botany 116: 377-379.

Franco, M. and Silvertown, J. 2004. A Comparative demography of plants based upon elasticities of vital rates. Ecology 85 (2): 531-538.

Gonneau, C.; Jersáková, J., de Tredern, E., Till-Bottraud, I., Saarinen, K., Sauve, M., Roy, M., Hájek, T. and Selosse, M.-A. 2014. Photosynthesis in perennial mixotrophic Epipactis spp. (Orchidaceae) contributes more to shoot and fruit biomass than to hypogeous survival. Journal of Ecology 2014, 102, 1183-1194

Gregg, K.B. 2004. Recovery of showy lady's slippers (Cypripedium reginae Walter) from moderate and severe herbivory by white-tailed deer (Odocoileus virginianus Zimmerman) Natural Areas Journal 24 (3): 232-241.

Jacquemyn, H.; Brys, R., Lievens, B. and Wiegand, T. 2012. Spatial variation in below-ground seed germination and divergent mycorrhizal associations correlate with spatial segregation of three co-occurring orchid species. Journal of Ecology 100: 1328-1337.

JMP $^{\circledR}$, Pro 10. SAS Institute Inc., Cary, NC, 1989-2012.

Johnson,C.E.; Driscoll, C.T., Siccama, T.G. and Likens, G.E. 2000. Element fluxes and landscape position in a northern hardwood forest watershed ecosystem. Ecosystems 3: 159-184. 
Knapp, W.M. and Wiegand, R. 2014. Orchid (Orchidaceae) decline in the Catoctin Mountains, Frederick County, Maryland as documented by a long-term dataset. Biodiversity and Conservation 23:1965-1976.

Likens, G.E. and Bormann, F.H. 1995. Biogeochemistry of a Forested Ecosystem. Second Edition, Springer-Verlag New York Inc.

Mathworks. 2015. MATLAB and Statistics Toolbox Release 2015a, The MathWorks, Inc., Natick, Massachusetts, United States.

MINITAB. 2003. MINITAB 14 Statistical Software. MINITAB, Inc. State College, PA (www.minitab.com)

McCormick, M.K. and Jacquemyn, H. 2014. What constrains the distribution of orchid populations? New Phytologist 202: 392-400.

McCormick, M.K.; Taylor, D.L., Juhaszova, K., Burnett Jr, R.K., Whigham, D.F. and O’Neill, J.P. 2012. Limitations on orchid recruitment: not a simple picture. Molecular Ecology 21: 15111523. 
NatureServe. 2015. NatureServe Explorer: An online encyclopedia of life [web application]. Version 7.1. NatureServe, Arlington, Virginia. Available http://explorer.natureserve.org. (Accessed: December 26, 2015).

Payton, M.E.; Greenstone, M.H. and Schenker, N. 2003. Overlapping confidence intervals or standard error intervals: What do they mean in terms of statistical significance? Journal of Insect Science. 3: 34 .

Pletscher, D.H.; Bormann, F.H. and Miller, R.S. 1989. Importance of deer compared to other vertebrates in nutrient cycling and energy flow in a northern hardwood ecosystem. American Midland Naturalist 121 (2): 302-311.

Rasmussen H.N; Dixon, K.W. Jersáková, J. and Těšitelová, T. 2015. Germination and seedling establishment in orchids: a complex of requirements. Annals of Botany 116: 391-402.

Reddoch, A.H. and Reddoch, J.M. 1993. The species pair Platanthera orbiculata and $P$. macrophylla (Orchidaceae): taxonomy, morphology, distributions and habitats. Lindleyana 8(4): $171-187$. 
Reddoch, J.M. and Reddoch, A.H. 1997. The orchids in the Ottawa District: Floristics, phytogeography, population studies and historical review. Canadian Field-Naturalist 111 (1): 1185.

Reddoch, J.M. and Reddoch, A.H. 2007. Population Ecology of Platanthera Hookeri (Orchidaceae) in southwestern Quebec, Canada. Journal of the Torrey Botanical Society, 134:369-378.

Scheiner, S.M. and Gurevitch, J.C. 1993. Design and analysis of ecological experiments. Chapman and Hall, New York, NY. 445 p.

Shefferson, R.P.; Kull, T. and Tali, K. 2005. Adult whole-plant dormancy induced by stress in long-lived orchids. Ecology 86: 3099-3104.

Sheviak, C.J. 2003. Platanthera In: Flora of North America Editorial Committee, eds. 2003. Flora of North America North of Mexico. New York and Oxford. Vol. 26, pp. 551555.

USDA, NRCS. 2015. The PLANTS Database (http://plants.usda.gov, 26 December 2015). National Plant Data Team, Greensboro, NC 27401-4901 USA.

van Doorn, N.S.; Battles, J.J., Fahey, T.J., Siccama, T.G. and Schwarz, P.A. 2011. Links between biomass and tree demography in a northern hardwood forest: a decade of stability and change in Hubbard Brook Valley, New Hampshire. Can. J. For. Res. 41: 1369-1379. 
Yagame, T.; Orihara, T., Selosse, M.-A., Yamato, M. and Iwase, K. 2012. Mixotrophy of Platanthera minor, an orchid associated with ectomycorrhiza-forming Ceratobasidiaceae fungi. New Phytologist 193: 178-187.

Zelmer, C.D.; Cuthbertson, L. and Currah, R.S. 1996. Fungi associated with terrestrial orchid mycorrhizas, seeds and protocorms. Mycoscience 37: 439-448. 
Table 1. Summary of the number of marked orchid individuals for Platanthera macrophylla and P. orbiculata with measurements during the five years of the study.

\begin{tabular}{lccc}
\hline Year & P. macrophylla & P. orbiculata & Both species \\
\hline $\mathbf{2 0 1 1}$ & 100 & 86 & $\mathbf{1 8 6}$ \\
$\mathbf{2 0 1 2}$ & 88 & 77 & $\mathbf{1 6 5}$ \\
$\mathbf{2 0 1 3}$ & 119 & 104 & $\mathbf{2 2 3}$ \\
$\mathbf{2 0 1 4}$ & 129 & 144 & $\mathbf{2 7 3}$ \\
$\mathbf{2 0 1 5}$ & 129 & 143 & $\mathbf{2 7 2}$ \\
All years & 192 & 194 & $\mathbf{3 8 6}$ \\
Data in all years & 48 & 44 & $\mathbf{9 2}$ \\
\hline
\end{tabular}


Table 2. Comparison of fecundity parameters between the round-leaved orchid species pair Platanthera macrophylla and P. orbiculata. Values for parameters based on multiple years of observations were calculated based on the aggregate data for those years. Bold font indicates statistically significant differences $(P \leq 0.05)$ between the species from a likelihood-ratio $G^{2}$ test for the top two parameters and a $t$-test for the others.

\begin{tabular}{|c|c|c|c|c|c|}
\hline \multirow{2}{*}{ Fecundity Parameter } & \multirow{2}{*}{$\operatorname{Year}(\mathbf{s})$} & \multicolumn{2}{|c|}{ P. macrophylla } & \multicolumn{2}{|c|}{ P. orbiculata } \\
\hline & & Value & $(\mathrm{N})$ & Value & $(\mathbf{N})$ \\
\hline Proportion initiating inflorescence & $2011-15$ & 0.39 & $(411)$ & 0.48 & $(422)$ \\
\hline Proportion flowering & $2011-15$ & 0.28 & $(411)$ & 0.31 & $(422)$ \\
\hline Flowers / flowering plant & $2011-15$ & 13.9 & $(115)$ & 20.4 & $(131)$ \\
\hline Swollen ovaries / flowering plant & 2013 & 4.6 & (34) & 4.4 & $(24)$ \\
\hline Swollen ovaries / flower & 2013 & 0.33 & (34) & 0.22 & $(24)$ \\
\hline Fruits / flowering plant & $2013-15$ & 2.0 & $(87)$ & 2.5 & $(96)$ \\
\hline Fruit set / flowering plant & $2013-15$ & 0.14 & $(87)$ & 0.11 & $(96)$ \\
\hline
\end{tabular}




\section{Figure Legends}

Figure 1. Map of study area within Hubbard brook Experimental Forest and populations of round-leaved orchids, Platanthera macrophylla and P. orbiculata. On the inset of the state of New Hampshire, the study site location is marked by an " $\mathrm{X}$ ". The scale of the map precluded depiction of all study individuals, but rather provides the visual extent of the populations and their occurrence on the landscape. This map was created by Scott Bailey in ARC-GIS from publicly available GIS data (http://www.hubbardbrook.org/gis/) and is used here with permission.

Figure 2. Stage-structured life cycle graph for the species pair Platanthera macrophylla and $P$. orbiculata. Aboveground stages are primarily defined by leaf morphology and size (Figure 3), and the presence or absence of an inflorescence for adults. Life-history stage transitions are indicated by arrows with solid lines and reproduction is indicated by dashed lines.

Figure 3. Differences in leaf area by demographic life stages for Platanthera macrophylla (M) and $P$. orbiculata (O). Box plots show the median (white mid-line), 75\% spread (Black box) 95\% spread (vertical lines) and outliers (dots). Significant differences between leaf area by life stages are shown with capital letters for Steel-Dwass between pairs post-hoc comparisons $(\alpha=$ $0.05)$. 
Figure 4. Comparison of vital demographic rates between P. macrophylla and P. orbiculata. Shown are the proportions of individuals for each demographic transition based on aggregate data from 2011-2015. Asterisks $(*)$ indicates statistically significant differences $(P \leq 0.05)$ in a vital rate between the two species based on likelihood-ratio $G^{2}$ tests.

Figure 5. Age-specific survivorship starting from the Juvenile stage for P. macrophylla (black) and $P$. orbiculata (gray). To illustrate survivorship through the different stage classes (figure 2), dashed vertical lines have been added to denote the average time that surviving individuals spend within each of the life history stages of Juvenile, Immature, and Adult (flowering and nonflowering). Note that the last set of dashed lines also corresponds with the average age at death (i.e. life expectancy) of survivors through all the stage classes.

Figure 6. Comparison of leaf surface damage grouped by demographic transitions (left) and year (right) for Platanthera macrophylla $(\mathrm{M})$ and $P$. orbiculata $(\mathrm{O})$. Box plots show the median (white mid-line), 75\% spread (Black box) 95\% spread (vertical lines) and outliers (dots). Significant differences between leaf area by life stages are shown with capital letters for SteelDwass between pairs post-hoc comparisons $(\alpha=0.05)$. 
Figure 7. Summary of damage agents on leaves of round-leaved orchids, Platanthera marcophylla and P. orbiculata. A) percent of marked individuals with damage by these agents. The percentages are percentage of total with all years combined. B) percent of leaf area damaged by the source. Box plots show the median (white mid-line), 75\% spread (Black box) 95\% spread (vertical lines) and outliers (dots). Significant differences between leaf area by life stages are shown with capital letters for Steel-Dwass between pairs post-hoc comparisons $(\alpha=$ $0.05)$. 


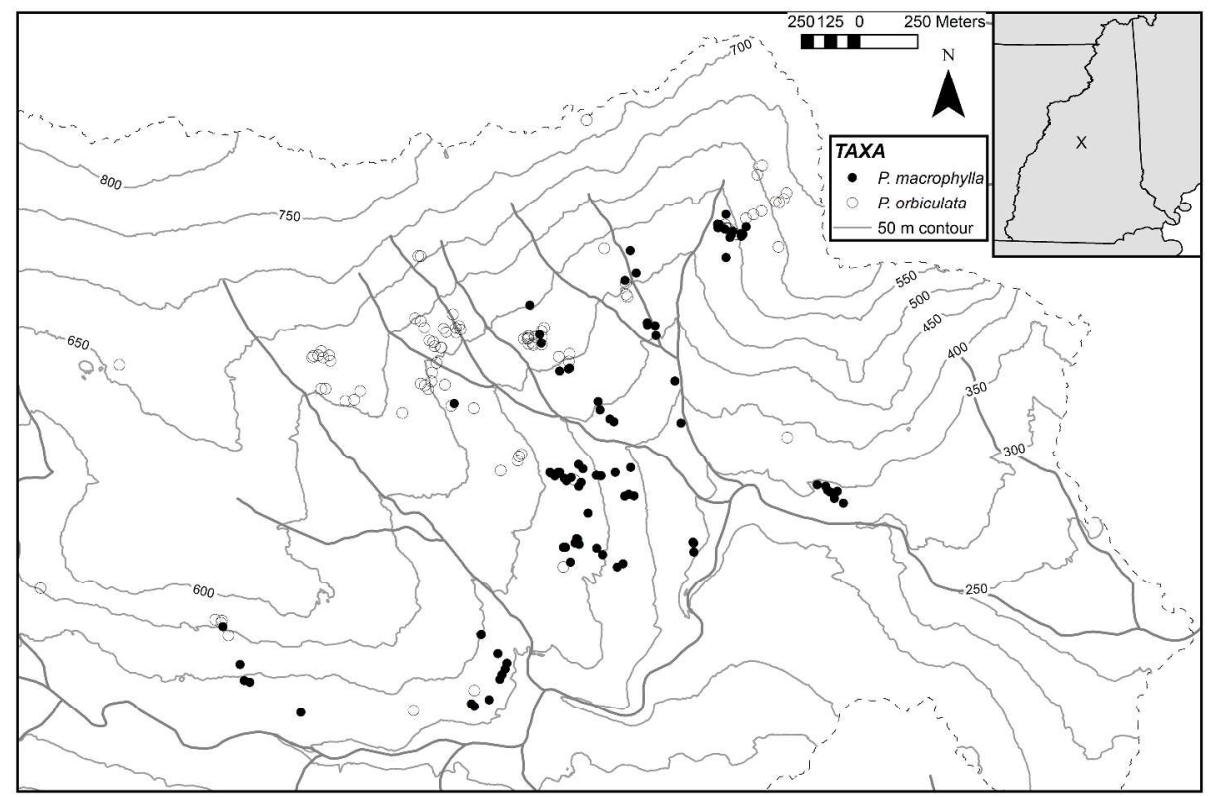

Figure 1. Map of study area within Hubbard brook Experimental Forest and populations of round-leaved orchids, Platanthera macrophylla and P. orbiculata. On the inset of the state of New Hampshire, the study site location is marked by an "X". The scale of the map precluded depiction of all study individuals, but rather provides the visual extent of the populations and their occurrence on the landscape. This map was created by Scott Bailey in ARC-GIS from publicly available GIS data and is used here with permission. 


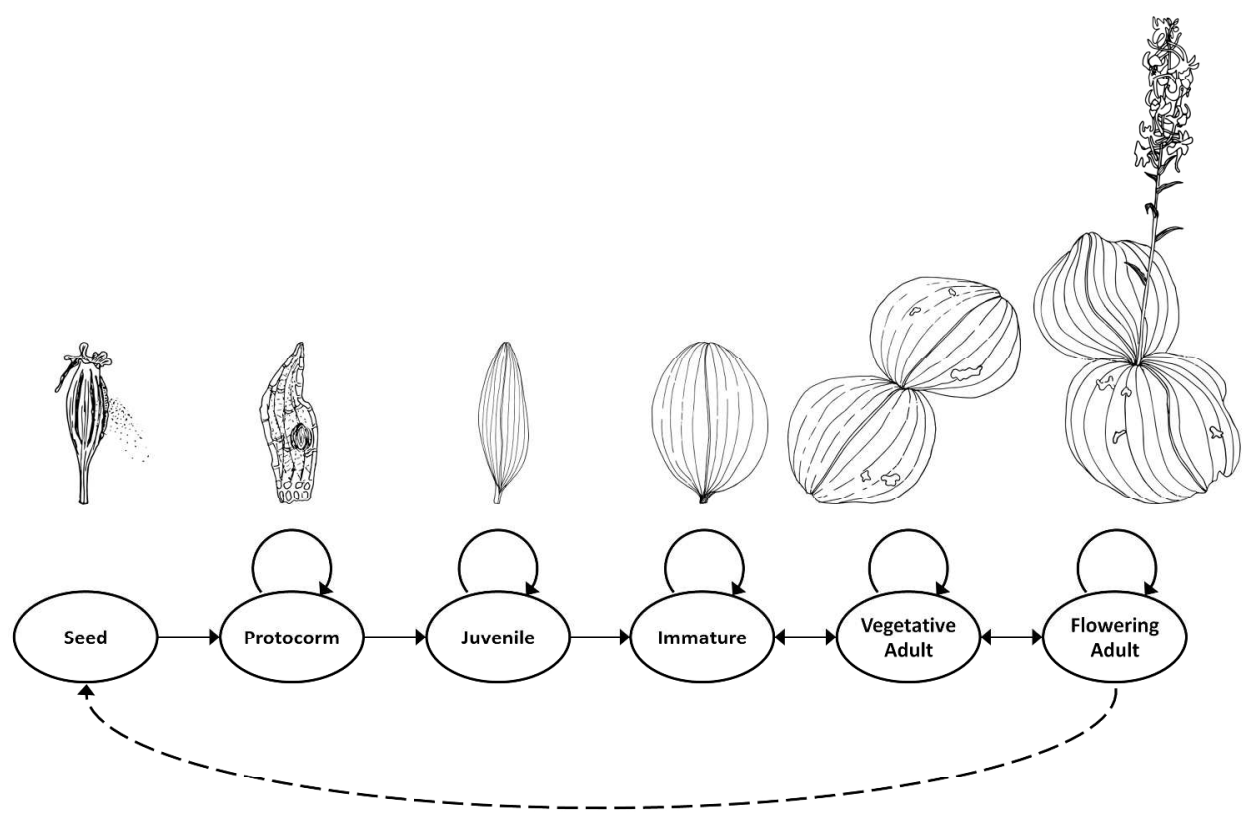

Figure 2. Stage-structured life cycle graph for the species pair Platanthera macrophylla and P. orbiculata. Aboveground stages are primarily defined by leaf morphology and size (Figure 3 ), and the presence or absence of an inflorescence for adults. Life-history stage transitions are indicated by arrows with solid lines and reproduction is indicated by dashed lines.

$254 \times 190 \mathrm{~mm}(300 \times 300 \mathrm{DPI})$ 


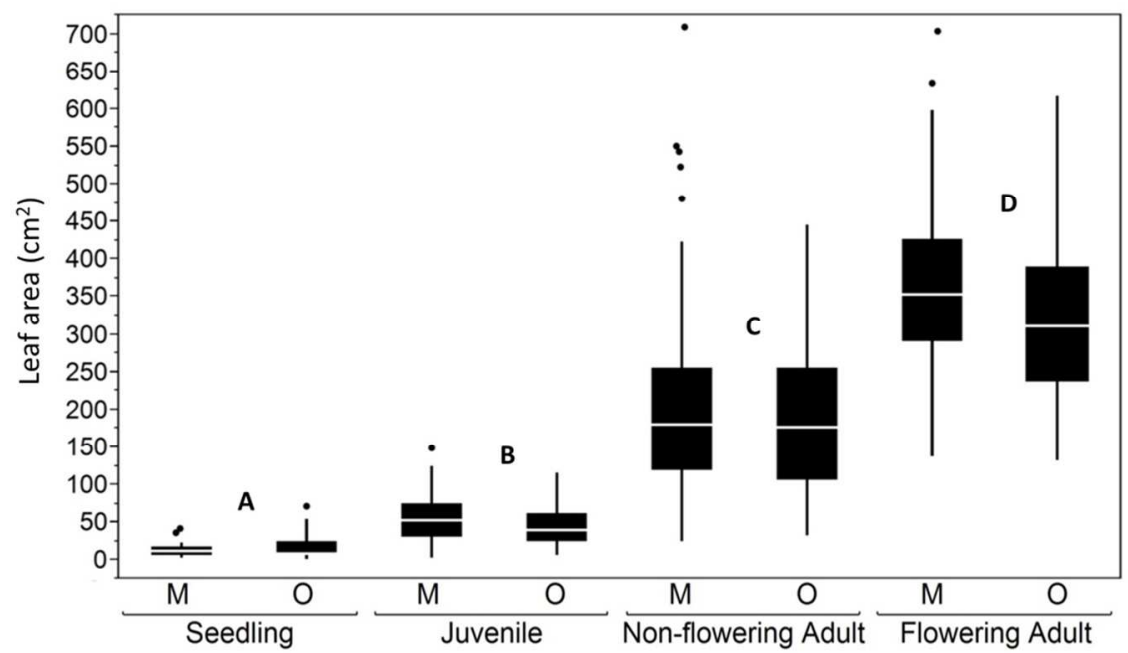

Figure 3. Differences in leaf area by demographic life stages for Platanthera macrophylla (M) and P. orbiculata (O). Box plots show the median (white mid-line), 75\% spread (Black box) $95 \%$ spread (vertical lines) and outliers (dots). Significant differences between leaf area by life stages are shown with capital letters for Steel-Dwass between pairs post-hoc comparisons $(a=0.05)$.

$101 \times 57 \mathrm{~mm}(300 \times 300$ DPI $)$ 


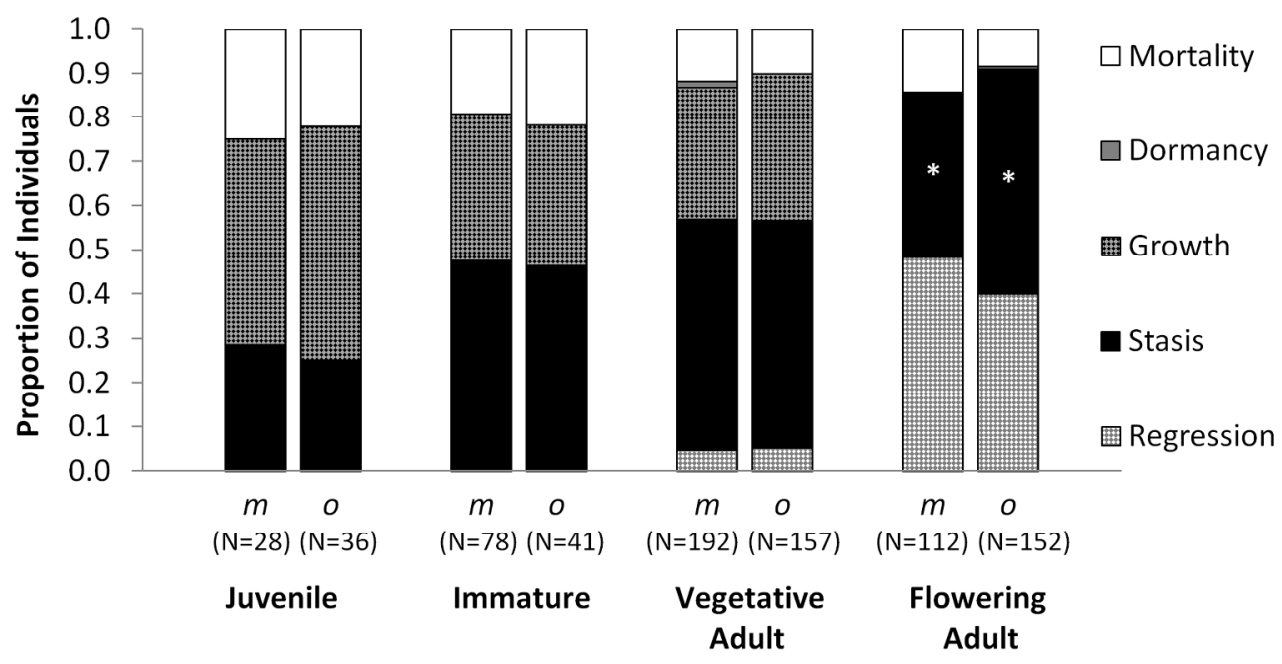

Figure 4. Comparison of vital demographic rates between P. macrophylla and P. orbiculata. Shown are the proportions of individuals for each demographic transition based on aggregate data from 2011-

2015. Asterisks $(*)$ indicates statistically significant differences $(P \leq 0.05)$ in a vital rate between the two species based on likelihood-ratio G2 tests.

$190 \times 101 \mathrm{~mm}(300 \times 300$ DPI $)$ 


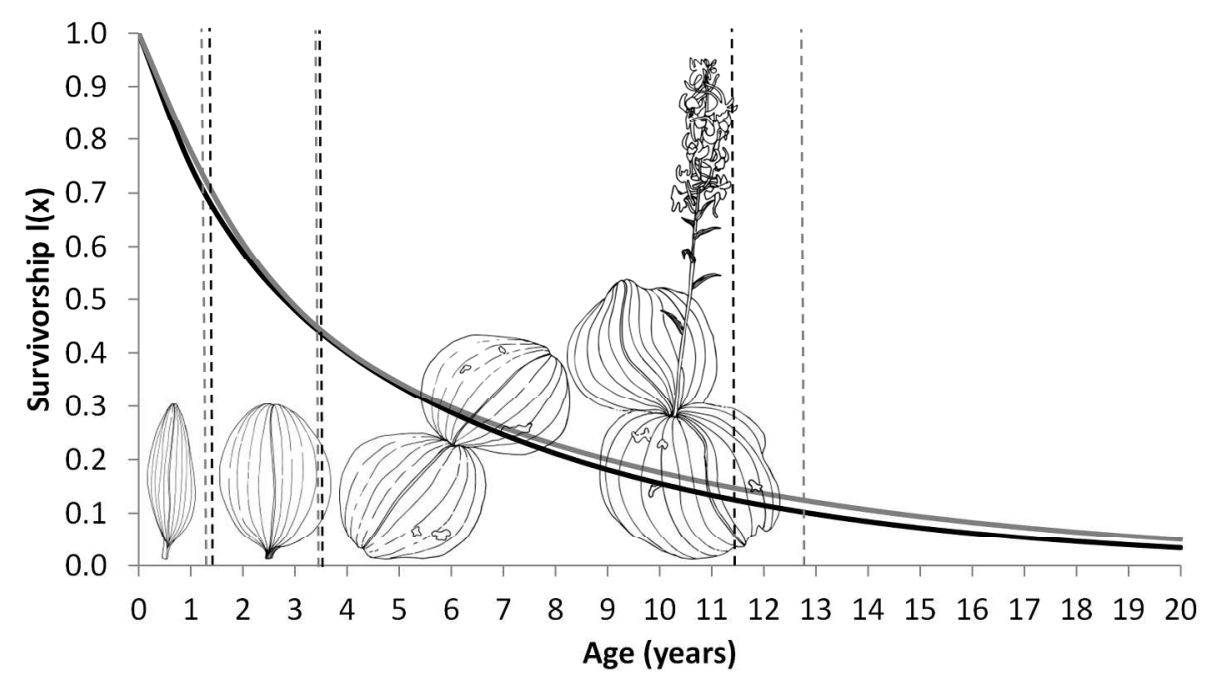

Figure 5. Age-specific survivorship starting from the Juvenile stage for $P$. macrophylla (black) and $P$. orbiculata (gray). To illustrate survivorship through the different stage classes (figure 2), dashed vertical lines have been added to denote the average time that surviving individuals spend within each of the life history stages of Juvenile, Immature, and Adult (flowering and non-flowering). Note that the last set of dashed lines also corresponds with the average age at death (i.e. life expectancy) of survivors through all the stage classes.

$190 \times 101 \mathrm{~mm}(300 \times 300$ DPI $)$ 

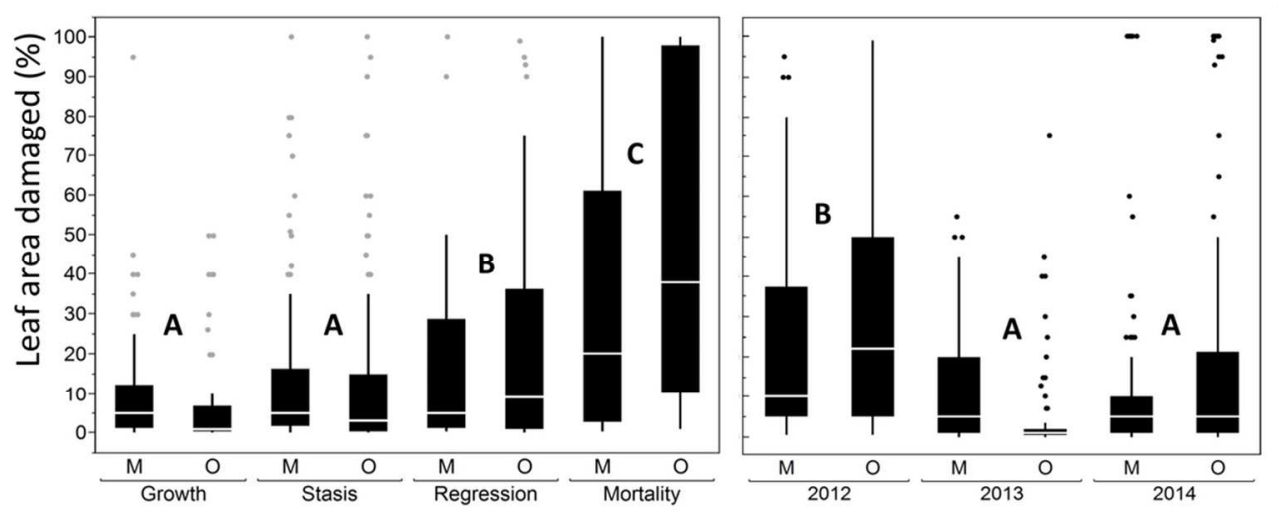

Figure 6. Comparison of leaf surface damage grouped by demographic transitions (left) and year (right) for Platanthera macrophylla (M) and P. orbiculata (O). Box plots show the median (white mid-line), $75 \%$ spread (Black box) 95\% spread (vertical lines) and outliers (dots). Significant differences between leaf area by life stages are shown with capital letters for Steel-Dwass between pairs post-hoc comparisons $(a=0.05)$.

$$
101 \times 40 \mathrm{~mm}(300 \times 300 \mathrm{DPI})
$$



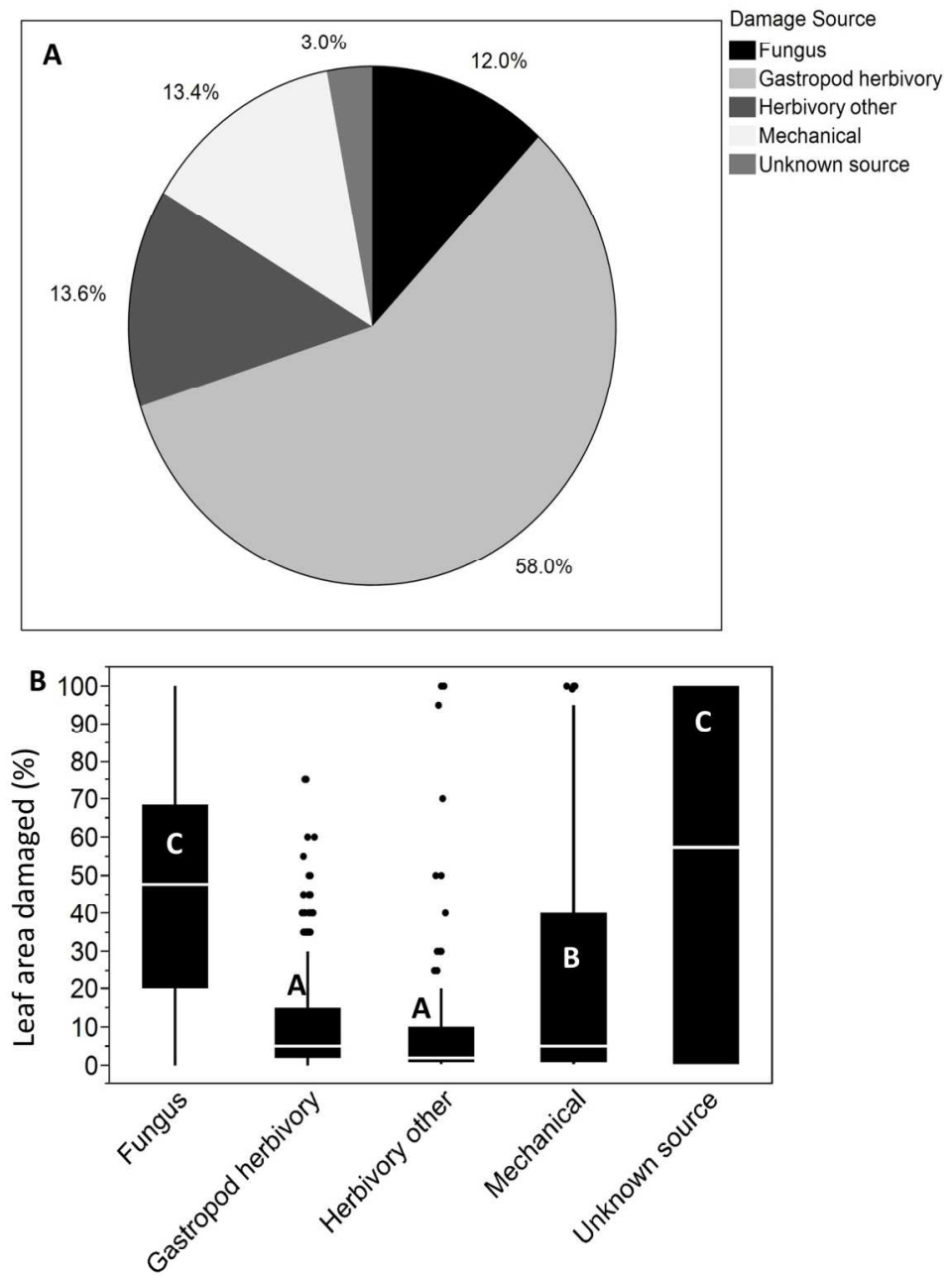

Figure 7. Summary of damage agents on leaves of round-leaved orchids, Platanthera marcophylla and $P$. orbiculata. A) percent of marked individuals with damage by these agents. The percentages are percentage of total with all years combined. B) percent of leaf area damaged by the source. Box plots show the median (white mid-line), 75\% spread (Black box) 95\% spread (vertical lines) and outliers (dots). Significant differences between leaf area by life stages are shown with capital letters for Steel-Dwass between pairs post-hoc comparisons $(a=0.05)$.

$203 \times 325 \mathrm{~mm}(300 \times 300$ DPI) 
Table A1. Comparison of damage source occurrence by year for round-leaved orchids in Hubbard Brook Experimental Forest, NH.

\begin{tabular}{llllll}
\hline Year & \multicolumn{2}{l}{ Damage source } & & \\
& Fungus & $\begin{array}{l}\text { Gastropod } \\
\text { herbivory }\end{array}$ & $\begin{array}{l}\text { Other } \\
\text { herbivory }\end{array}$ & Mechanical & $\begin{array}{l}\text { Unknown } \\
\text { source }\end{array}$ \\
\hline 2012 & 25.4 & 66.7 & 4.3 & 2.9 & 0.7 \\
2013 & 7.4 & 64.5 & 5.6 & 17.7 & 4.8 \\
2014 & 6.1 & 37.4 & 37.4 & 16.8 & 2.3 \\
\hline
\end{tabular}




\section{Appendix Figure Legends}

Figure A1. Projection matrices (A) and corresponding fundamental matrices (N), which indicates the average time each species spends in a given life-history stage. The sum of each column in the fundamental matrices provides the average age at death (i.e., life expectancy) for each stage. The four stages included in these matrices are Juvenile, Immature, Vegetative Adult, and Flowering Adult.

Figure A2. Comparison of vital demographic rates between P. macrophylla and P. orbiculata. Shown are the proportions of individuals for each demographic transition for the years 20112015. Asterisks $(*)$ indicates statistically significant differences $(P \leq 0.05)$ in a vital rate between the two species based on likelihood-ratio $G^{2}$ tests. Note: sample sizes for seedlings in 2011-12 and 2012-13, and dormancy in adults (all years) were too small to conduct statistical analyses.

Figure A3. Comparison of leaf surface damage grouped by life stage for Platanthera macrophylla $(\mathrm{M})$ and P. orbiculata $(\mathrm{O})$. Box plots show the median (white mid-line), 75\% spread (Black box) 95\% spread (vertical lines) and outliers (dots). 


$$
\begin{aligned}
& \text { P. macrophylla } \\
& \mathbf{A}=\left(\begin{array}{cccc}
0.286 & 0 & 0 & 0 \\
0.464 & 0.474 & 0.046 & 0 \\
0 & 0.333 & 0.523 & 0.482 \\
0 & 0 & 0.297 & 0.375
\end{array}\right) \quad \mathbf{N}=\left(\begin{array}{cccc}
1.40 & 0 & 0 & 0 \\
1.40 & 2.15 & 0.40 & 0.31 \\
1.88 & 2.89 & 4.57 & 3.52 \\
0.89 & 1.37 & 2.17 & 3.27
\end{array}\right) \\
& \text { P.orbiculata } \\
& \mathbf{A}=\left(\begin{array}{cccc}
0.250 & 0 & 0 & 0 \\
0.528 & 0.463 & 0.051 & 0 \\
0 & 0.317 & 0.516 & 0.399 \\
0 & 0 & 0.331 & 0.510
\end{array}\right) \quad \mathbf{N}=\left(\begin{array}{cccc}
1.33 & 0 & 0 & 0 \\
1.53 & 2.17 & 0.52 & 0.42 \\
2.25 & 3.20 & 5.42 & 4.42 \\
1.52 & 2.16 & 3.66 & 5.02
\end{array}\right)
\end{aligned}
$$

$190 \times 101 \mathrm{~mm}(300 \times 300 \mathrm{DPI})$ 

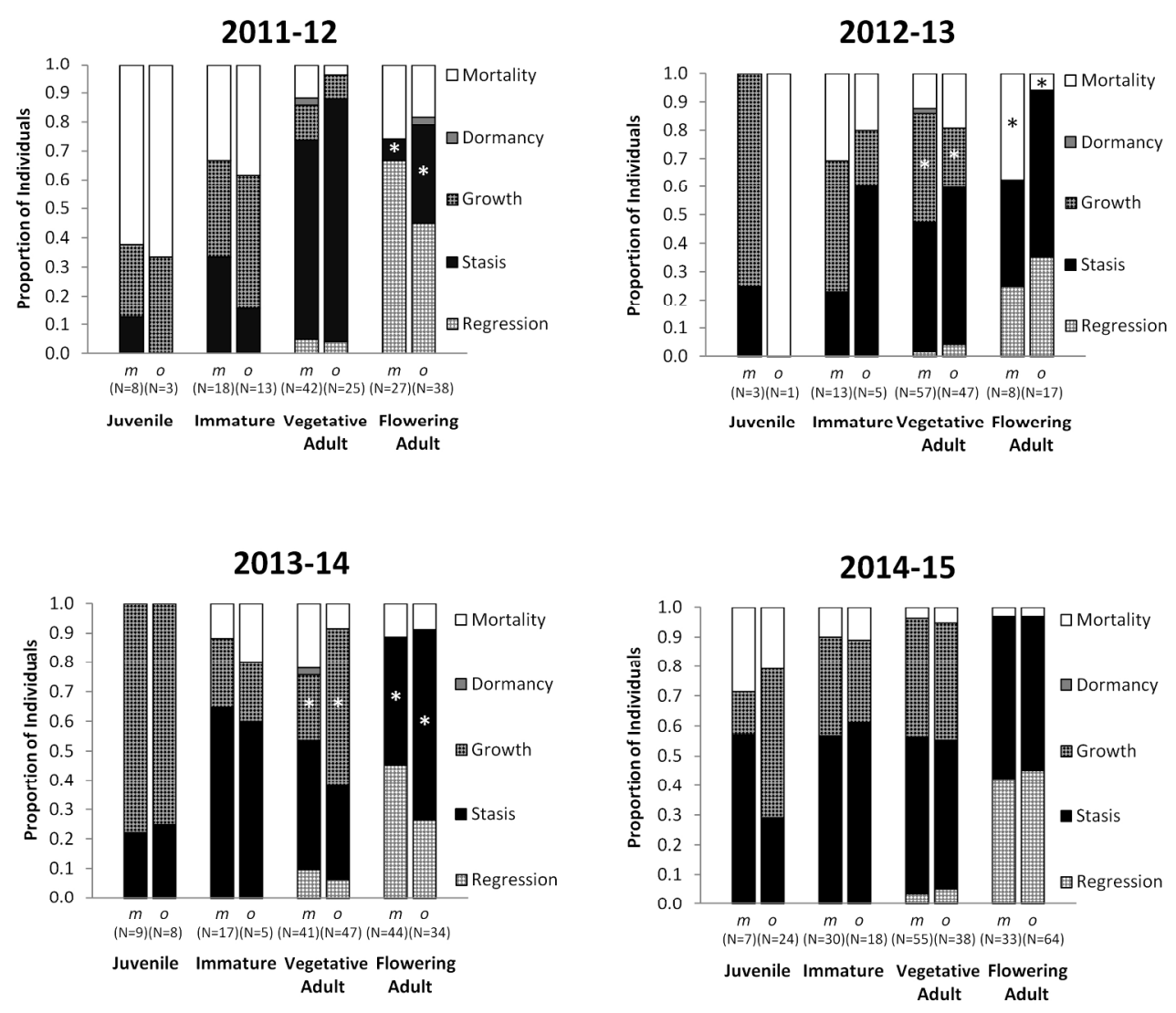

$215 \times 215 \mathrm{~mm}(300 \times 300$ DPI $)$ 


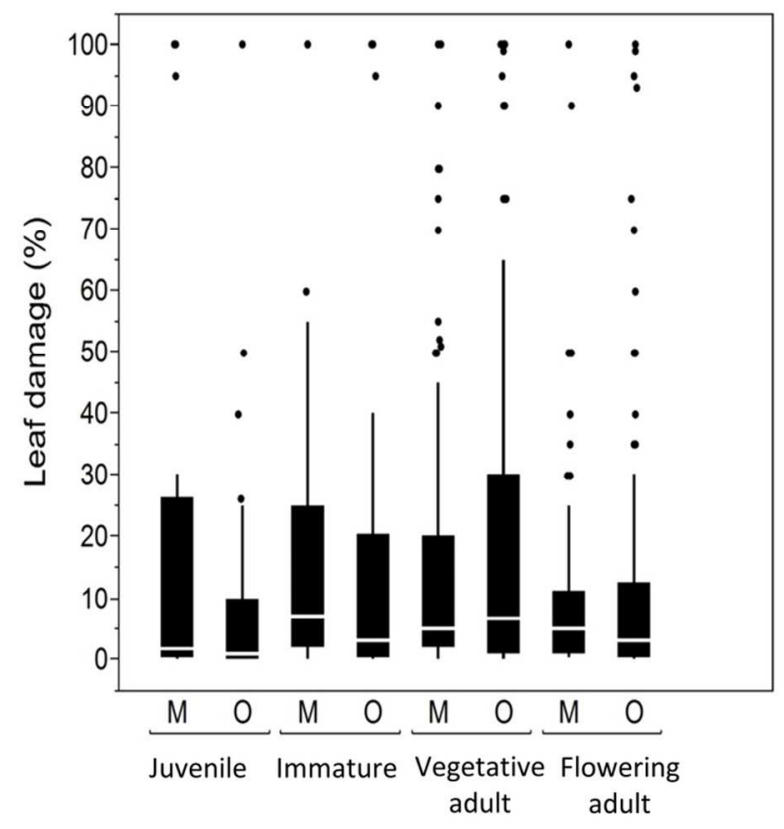

$101 \times 67 \mathrm{~mm}(300 \times 300 \mathrm{DPI})$ 